San Jose State University

SJSU ScholarWorks

Master's Projects

Master's Theses and Graduate Research

5-1-2005

\title{
Analysis of Contraceptive Self-Efficacy in Clients Requesting Emergency Contraception
}

Jennifer L. Nordeen

San Jose State University

Follow this and additional works at: https://scholarworks.sjsu.edu/etd_projects

Part of the Other Nursing Commons

\section{Recommended Citation}

Nordeen, Jennifer L., "Analysis of Contraceptive Self-Efficacy in Clients Requesting Emergency

Contraception" (2005). Master's Projects. 800.

DOI: https://doi.org/10.31979/etd.pmp5-rj3f

https://scholarworks.sjsu.edu/etd_projects/800

This Master's Project is brought to you for free and open access by the Master's Theses and Graduate Research at SJSU ScholarWorks. It has been accepted for inclusion in Master's Projects by an authorized administrator of SJSU ScholarWorks. For more information, please contact scholarworks@sjsu.edu. 
SAN JOSE STATE UNIVERSITY

SCHOOL OF NURSING

\section{MASTER'S PROGRAM PROJECT OPTION (PLAN B) PROJECT SIGNATURE FORM}
STUDENT NAME
Jennifer L. Nordeen

SEMESTER ENROLLED

TITLE OF PROJECT Analysis of Contraceptive Self-Efficacy in Clients Requesting Emergency

NAME OF JOURNAL JOGNN - Journal of Obstetric, Gynecologic The project and manuscript have been successfully completed and meet the standards of the School of Nursing at San Jose State University. The project demonstrates the application of professional knowledge, clinical expertise, and scholarly thinking. An abstract of the project and two copies of the manuscript are attached.
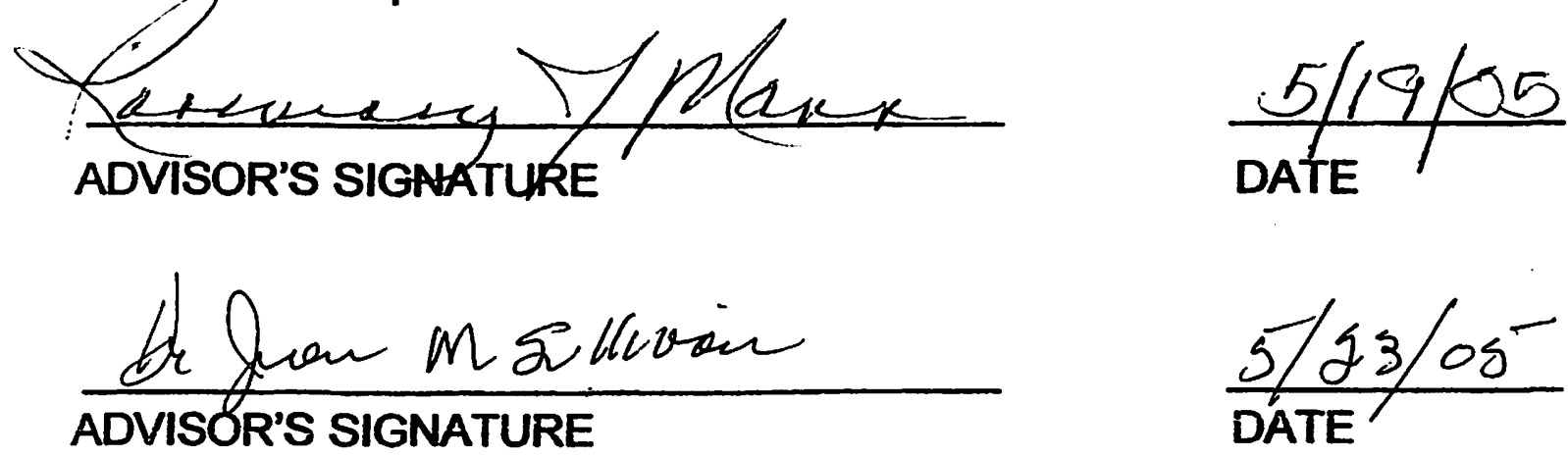

Please submit this form to the Graduate Coordinator. Attach abstract, two copies of the manuscript, and documentation of submission to the journal (i.e., postal receipt). 


\section{Phyllis Connolly}

\section{From:}

Sent: Wednesday, May 25, 2005 10:31 AM

To: $\quad$ Phyllis Connolly

Subject: Manuscript submission

Dr Connolly,

I got it to process my submission this morning. YEAH!!!! Do you need anything else from me?

Jennifer Nordeen

Submissions Being Processed for Author Jennifer Louise Nordeen, RN MSN

\begin{tabular}{|c|c|c|c|c|c|}
\hline Action & $\begin{array}{l}\text { Manuscript } \\
\text { Number }\end{array}$ & Title & \begin{tabular}{|l|} 
Initial \\
Date \\
Submitted \\
\end{tabular} & $\begin{array}{l}\text { Status } \\
\text { Date }\end{array}$ & $\begin{array}{l}\text { Current } \\
\text { Status }\end{array}$ \\
\hline View Submission & & \begin{tabular}{|l|} 
Analysis of \\
Contraceptive Self- \\
Efficacy in Clients \\
Requesting \\
Emergency \\
Contraception
\end{tabular} & $05 / 25 / 2005$ & 05/25/2005 & $\begin{array}{l}\text { Submitted } \\
\text { to Journal }\end{array}$ \\
\hline
\end{tabular}

Back to Main Menu

You should use the free Adobe Acrobat Reader 6 or later for best PDF Viewing results.

74. 1 Get Acrobat 
Subj: (no subject)

Date: $\quad$ 5/24/2005 9:14:24 A.M. Pacific Standard Time

From: Jennifer nordeen

To:

CC:

JOGNN Editorial Manager

While attempting to attach my manuscript for submission I received a message that an error occurred while processing my request. What do I need to do to process my submission? Please let me know ASAP

Jennifer Nordeen 


\section{EMEditorial Manager"}

Sorry, an error has occurred while processing your request. Details of the error have been sent to Editorial Manager engineers. 


\section{TRANSFER OF COPYRIGHT}

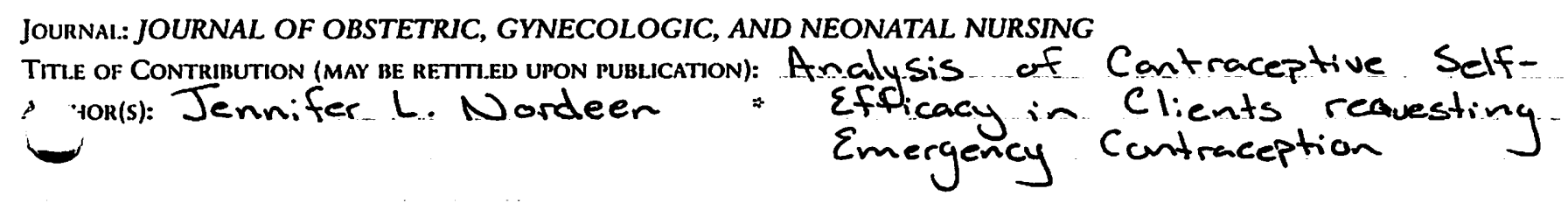

" The "Corresponding Author," nuthorized to communicate with the Editor of the Journal on trehalf of all the Authors

Note: If the Contribution. or any Author's work contained in the Contriburion, is a "work made for hire" (that is, writren by the Author while an employet and within the scope of the Author's employment), then the Author's employer owns the copyright in the Author's work conrained in the Contribution and must also sign his Transfer.

E.MPI.OTER:

All the Authors of the Contribution (and Employer, if applicable), jointly and severally, are referred to as the "Contributor."

The Journal is owned by the Association of Women's Health, Obstetric and Neonatal Nurses (AlWHONN) and puhlished by Sage Publications, Inc., 24.55 Teller Road. Thousand Oaks. CA 91320, USA (the "Publisher"). AWHONN is pleased to consider the Contribution for publication in the journal. If and when the Contribution is accepted for publication in the Journal, the following terms and conditions shall become effective as of the date of Contributer's execution of this Transfer:

Transfer of Copyright: Contributor transfers and assigns to AWHONN all right, tirle, and interest of every kind in and to the copyright in the Contribution for the full term of copyright throughout the world, together with all the exclusive rights comprised in such copyright and remedies as afforded by law (for United States government employees, to the extent allowable hy law), including, withour limitation, the exclusive right: to register the copyright in AlWHONN's name; to reproduce, publish, transmir, distribute, and publicly display and perform copies of the Consribution or excerpes therefrom, in any format or medium, and by any methed, device, or process, now known or later conceived or developed: to prepare translations and other derivative works based on the Contribution; and to license, iransfer, or assign to others any or all of the rights comprised in the copyright in the Consribution.

AlWHONN makes no guarantec that the Contribution will be published in the Journal. If, for any reasom, a final decision is made not to publish the Contribution in the Jeurnal, all rights in the coppright in the Consribution shall revert to Conrriburor, and this Trunsfict shall be of mo further force and effert and neither AVWHONN or Contribusor will have any obligation to the other with respect to the Contribution.

License to Contributor: AWWHONN grants back to Contriburor the non-exclusive license to: (a) use all or part of the Contribution (after publication in the Jo in any hook or article written hy the Aurhor(s), and (h) make photocokb all or part of the Contributisn for use by the Author(s) in classroum reaching. As a condition for this lictnse to Contriburor, all such books and artiIles containing the Contribution or any part theresf, and all photocopies of the Contribution or an! parn thereof, must include the copyright notice that appears on the issur of the Journal in which the Contribution is first published and a full citation of the Journal.

Contributor's Duties: (a) If the Contribution contains cospyrighted material not owned by Contrihuror, then Consributor shall obtain written permission from the copyright owner, in a form acceptable to AWHONN, to include such copyighted material in the Contribution and to reprint it in the Journal and in any ormat or medium and hy any methed, device or process, now known or later :onceived or developed, and shall deliver such wrinten permission to the Editor ogether with delisery of the manuseript of the Contribution. (b) The Editor nay copvedir the Contrihution for clarity, accuracy, length, publication style ind standard English use. The ediring can range from simple changes in a headine to extensive gondensing and redrafting of the article. In all censes, every
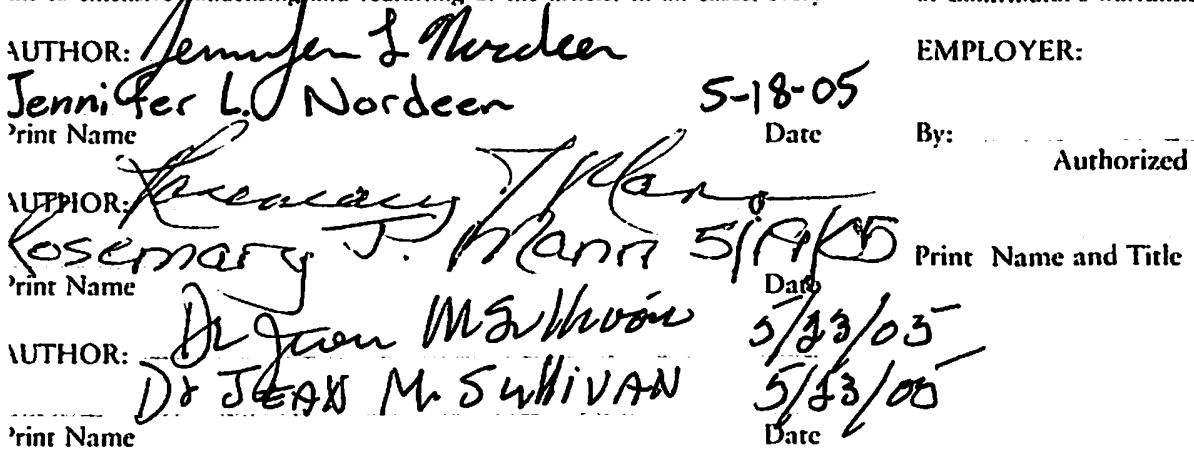

attempt will be made to have the author review the final edited manuscript. although AlWHONN and the Publisher reserve the right to recognize that in all cases this will nor be possible. The Publisher may charge to Contributor the cost of exrensive changes in proofs made by the Corresponding Author at a rate of \$2.00 per line. (c) This Transfer must be signed by each Aurhor (and Employer, if applicable) and delivered to the Editor as a condition for publication of the Contriburion in the Journal.

Credit; Use Of Name and Likeness: Each Author will reccive credit as an author of the Contribution when it is published in the Journal; the form and placement of the credit will be determined by AWHONN. Fach Author grants AWHONN and the Publisher the right to use his/her name, likeness, biographical information, and professional affiliations in connection with the publicarion and promotion of the Contribution and the Journal.

Consideration: In addition to publication of the Contriburion in the Journal. the Publisher will provide the Corresponding Auther ten (10) copies of the issue of the Journal in which the Contribution is first published. Additional reprints of the Contribution may be purchased at the Publisher's regularly scheduled prices.

Warranties: Contributor warrants and represents that: (a) the Contriburion has nor been previously published, is not in the public domain, and is the original work of the Author(s) (except for excerpts from copyrighted material owned by others and included with the written permission of the copyright owner); (b) Contributor is the owner of all right, ritle, and interest of every kind in and to the copyright in the Contribution, and has the full power and authority to rransfer and assign the copyright to AlWHONN; (c) the Contrihution does not infringe the copyright or any other proprietary right of any party; (d) the Contribution contains no matcrial that is defamatory, violates any right of privacy. or is otherwise contrary to law; (c) all statements in the Contribution asserted as facts are based upon reasonable research for accuracy; (f) no formula or procedure contained in the Contribution would cause injury if used in accordance with the instructions and/or warnings contained in the Contribution; and (g) Contributor has ohrained and received JOGNN Author Guidelines. Contriburor shall indemnify AlVHONN and the Publisher, its subsidiaries and affiliates. their officers, directors, employees, agents, and licensecs, against any liabilities. costs, and expenses (including reasonable legal fees and court costs) resulting from any claim finally sustained or sctrled based on facts inconsistent with any of Contrihuror's warrantics and representations.

\section{EMPLOYER:}

Authorized Officer 


\section{Running Head: SELF-EFFICACY IN EMERGENCY CONTRACEPTION}


Running Head: SELF-EFFICACY IN EMERGENCY CONTRACEPTION

Author Identification Notes

Jennifer Nordeen RN MSN

9 Staff Nurse II, Kaiser Permanente, Labor and Delivery, Santa Clara, CA

10 Clinical Systems RN, Planned Parenthood Mar Monte, San Jose, CA

11 Obstetrics Clinical Nursing Instructor, San Jose State University, San Jose, CA

12 Obstetrics Clinical Nursing Instructor, Evergreen Valley College, San Jose, CA

13 
Running Head: SELF-EFFICACY IN EMERGENCY CONTRACEPTION

Abstract

14 Objective: To analyze the level of contraceptive self-efficacy in women

15 requesting emergency contraception (EC), and to suggest appropriate assessments

16 and interventions to promote optimal contraception.

17 Design: A quantitative survey administered to 55 clients requesting emergency

18 contraception over a 3-month time span.

19 Setting: One Planned Parenthood community clinic in San Jose, California.

20 Patients/Participants: Women who were 18 years or older, English speaking, and

21 requesting emergency contraception were asked to complete the survey by clinic

22 staff.

23 Interventions: No interventions were performed in the study. Implications for

24 practice are suggested by the interpretation of the survey data.

25 Main Outcome Measure(s): Participants scored high on the contraceptive self-

26 efficacy (CSE) scale in comparison with the normative samples.

27 Results: Clients in this setting requesting emergency contraception have a high

28 level of contraceptive self-efficacy.

29 Conclusion: Contraceptive counseling with clients requesting emergency

30 contraception should acknowledge their level of self-efficacy and allow for

31 mutual decision-making.

32 Keywords: contraceptive self-efficacy (CSE), emergency contraception (EC),

33 morning after pill, family planning, 
Running Head: SELF-EFFICACY IN EMERGENCY CONTRACEPTION

35 Method failures are always possible, but are usually preventable. (Callout should

36 appear with background and significance)

37 The population who is utilizing EC is an educated group of women. They adhere

38 to the recommended time constraints of EC, and have had a great amount of

39 experience with continuous birth control methods, yet they are not currently

40 utilizing a method. (Callout should appear with discussion)

41 Self-efficacy should be reinforced during interactions with these clients, but does

42 not necessarily require interventions aimed at increasing self-efficacy. (Callout

43 should appear with practice implications) 


\section{Running Head: SELF-EFFICACY IN EMERGENCY CONTRACEPTION}

Analysis of Contraceptive Self-Efficacy in

Clients Requesting Emergency Contraception

46 Background and Significance

47 Contraception is always a "hot topic". It becomes even more so when it

48 involves adolescents. It is not uncommon to have a Monday morning rush, in the

49 family planning clinic, with women requesting post-coital contraception or

50 emergency contraception (EC), after the clinic has been closed over the weekend.

51 Many of these women are adolescents. With the wide availability and near $100 \%$

52 efficacy of today's birth control methods, it is curious that EC is requested in the

53 quantity in which it is dispersed. In the literature related to EC many studies

54 discuss the effectiveness and availability of the method, but little else. There is

55 minimal published information regarding the characteristics of women utilizing

56 EC.

$57 \quad$ EC is suggested for use in the instance of a failure of a (barrier)

58 contraceptive method, or if no contraception is utilized at the time of intercourse,

59 when pregnancy is not desired. Anecdotal clinical observations show that it is

60 being used by sexually active women who are not using a contraceptive method

61 for unclear reasons, but that do not desire to become pregnant.

62 Optimal contraception would be abstinence, or the utilization of a reliable

63 continuous birth control method. Promotion of either of these methods may be 


\section{Running Head: SELF-EFFICACY IN EMERGENCY CONTRACEPTION}

64 appropriate for some and not for others. Accurate individual assessment is

65 needed to allow for appropriate intervention.

66 Many proponents of EC note in their studies that its $75-89 \%$ effectiveness

67 can greatly decrease unwanted pregnancies and elective abortions. (Coeytaux \&

68 Pillsbury 2001; Gold, Sucato, Conard, \& Hillard 2004; Grossman 2001; Hayes

69 Hutchings \& Hayes 2000; Roye \& Johnsen, 2002). The need for increased access

70 and utilization of EC is mentioned in the literature, but little is noted about how to

71 utilize client interaction to promote continual contraception.

72 Emergency contraception is a form of post-coital contraception that helps

73 to prevent pregnancy from occurring. The woman takes the prescribed amount of

74 oral hormones within the first 120 hours after unprotected intercourse when

75 pregnancy is not desired. Emergency contraception is not to be confused with

76 RU -486 or the abortion pill. If the woman has already become pregnant,

77 emergency contraception will not harm or terminate the pregnancy; it is only used

78 to prevent pregnancy from occurring. The methods of action are: inhibiting

79 ovulation, disrupting follicular development and/or interfering with the

80 maturation of the corpus luteum (Gold et al. 2004).

81 Occasionally there is confusion about EC. It is also known as the morning

82 after pill, or the Yuzpe regimen, Plan B or Preven (Gold et al. 2004). It was

83 originally a combination of high dose progesterone and estrogen in the form of

84 multiple pills of a 28-day pack of oral contraceptives and then repeating the dose 


\section{Running Head: SELF-EFFICACY IN EMERGENCY CONTRACEPTION}

8512 hours later. Progesterone only formulations, such as Plan B, balance high

86 efficacy and safety, with minimal side effects. Current recommendations from

87 the Society of Adolescent Medicine are to take the two prescribed tablets at once,

88 rather then waiting 12 hours before the second dose (Gold et al. 2004).

89 This article discusses the level of contraceptive self-efficacy (CSE) in

90 women requesting EC. CSE is defined by Levinson, Wan, \&Beamer (1998) as

91 the strength of conviction that a sexually active individual should and can control

92 sexual and contraceptive situations to achieve a contraceptively protected priority.

93 Emergency contraception, just as it is titled, is to be used in an "emergency". The

94 insight gained by the interpretation of the results of this study suggests

95 interventions related to the client's perceived ability to control sexual and

96 contraceptive situations and their utilization of EC.

97 When a client requests EC it is assumed that they either experienced a

98 contraceptive method failure, or that they weren't using a contraceptive method.

99 Method failures are always possible, but are usually preventable. Continuous

100 contraceptive methods are generally safe, efficacious and easily accessible. This

101 study analyzes the level of contraceptive self-efficacy (CSE) in clients requesting

102 emergency contraception in order to develop a better understanding of the

103 challenges perceived by these clients. The study also suggests appropriate

104 assessments and interventions based on data reflecting self-efficacy. 


\section{Running Head: SELF-EFFICACY IN EMERGENCY CONTRACEPTION}

\section{Literature Review}

107 Levinson (1986) initially developed the CSE tool to better understand the

108 characteristics of the contraceptively self-efficacious teenager. She used it with a

109 group of 258 female clients age 20 or younger in a family planning clinic in

110 Sunnyvale California. Effective contraception was reported as $23 \%$ for this

111 sample. In the factor analysis of the scale four factors emerged. These factors

112 were (a) conscious acceptance of sexual activity by planning for it, (b) assumption

113 of responsibility for the direction of sexual activity and for using contraception,

114 (c) assertiveness in preventing sexual intercourse in an involved situation and (d)

115 strong feelings of sexual arousal (Levinson 1986).

116 Levinson (1995b) utilized the research from the previous article and

117 results from a survey of 263 women age 20 or younger in a Chicago, Illinois

118 family planning clinic. These results were used to further analyze the CSE

119 construct in relation to reproductive and contraceptive knowledge (RCK) and

120 contraceptive behavior. In addition to the CSE tool, the respondents were asked

121 to provide information on contraceptive use, demographics, sexual experience, an

122 index of reproductive and contraceptive knowledge (IRCK), and psychosocial

123 factors. Results of this study found that the CSE statements are behaviorally

124 specific to the kinds of cognitive, emotional, and physical situations and demands

125 that teenage women experience over time in being sexually active and in trying to

126 use contraceptives. The data analysis of this study showed that CSE is related to 


\section{Running Head: SELF-EFFICACY IN EMERGENCY CONTRACEPTION}

127 contraceptive behavior, but did not show a direct relation between knowledge and

128 contraceptive practices. Effective contraception was reported as $30 \%$ for this

129 sample (Levinson 1995b).

130 The Sunnyvale and Chicago samples were compared with results of the

131 survey administered in two other settings. In Montreal by Bilodeau, Forget and

132 Tetreault (1994), the tool was translated into French and used with $2319^{\text {th }}$ and

$13310^{\text {th }}$ grade males and females in the classroom setting. Effective contraceptive use

134 was reported as $62 \%$ for the sexually active portion of this sample.

135 The tool was also used in the classroom setting in two separate studies and

136 results were combined into the American sample of 148 undergraduate college

137 males and females. Heinrich's (1993) study at a Northeastern university, and

138 Wright's (1992) study of black college students combined to create this college

139 sample for comparison with Sunnyvale, Chicago and Montreal. In both of these

140 College samples, Contraceptive Self-Efficacy scores were significantly related to

141 contraception and were the most important predictors of contraceptive use.

142 Effective contraception was reported as $21 \%$ for this sample.

143 In the data provided as normalization for possible clinical use of the items

144 the Chicago sample was omitted because of its variance in the response metric.

145 The Chicago sample used a 3-point scale whereas the other samples used a 5-

146 point scale. This comparison yielded recommendations for the further use of the

147 scale as a total item set with a 5-point scale for comparisons with the provided 


\section{Running Head: SELF-EFFICACY IN EMERGENCY CONTRACEPTION}

148 sample norms. A recommendation to extend CSE analyses to older adolescents

149 was also identified, as well as its use with a variety of young women's

150 contraceptive behaviors (Levinson Wan \&Beamer 1998).

$151 \quad$ Conceptual Framework

152 Bandura's (1986) research on self-efficacy serves as a theoretical

153 framework for this study. The motivational factors of the individual utilizing EC

154 are in question. The results of the survey uncover areas for further research and

155 implications for assessment and intervention related to the perceived self-efficacy

156 of women requesting EC. In Bandura's (1986) discussion of the self-efficacy

157 mechanism in human agency, the need for accurate appraisal of one's own

158 capabilities in order to facilitate successful functioning is highlighted. It is noted

159 that large misjudgments of personal efficacy in either direction have

160 consequences. Individuals who overestimate their capabilities can undertake

161 activities that are unmanageable; likewise, people tend to avoid tasks that are

162 perceived as exceeding their capabilities. It is noted by Bandura that "people who

163 regard themselves as highly efficacious act, think and feel differently from those

164 who perceive themselves as inefficacious. They produce their own future, rather

165 than simply foretell it." (p. 395)

166 In order to facilitate optimal contraception it is important to not only

167 identify the level of self-efficacy in clients but also to instigate a call to action.

168 Bandura (1986) discusses this relationship between self-efficacy judgment and 


\section{Running Head: SELF-EFFICACY IN EMERGENCY CONTRACEPTION}

169 action. Individuals must not only perceive themselves as efficacious, but they

170 must also embody the necessary subskills for the exercise of personal agency.

171 Even if an individual has the skills and a strong sense of self-efficacy they must

172 also perceive the task as important, and see an intrinsic or extrinsic incentive for

173 their performance.

174 Methodology

175 Design

176 This is a quantitative descriptive study to measure CSE in a convenience

177 sample of 55 clients requesting EC at one Planned Parenthood location. In

178 addition to the CSE survey, questions requesting background information from

179 the patients were asked.

180 Approval to carry out the study was obtained by San Jose State's

181 Institutional Review Board (IRB) as well as Planned Parenthood's Director of

182 Clinical Trials. Authorization to use the CSE tool was obtained from its author.

183 The Planned Parenthood clinic staff were informed of the study, and asked to

184 disperse the surveys to clients. The surveys were collected weekly, and the

185 results analyzed after a 55 completed surveys were obtained.

186 Participants were asked to read the informed consent, and completion of

187 the survey implied informed consent. Participation was anonymous and not

188 associated with the services rendered by Planned Parenthood. The participants 


\section{Running Head: SELF-EFFICACY IN EMERGENCY CONTRACEPTION}

189 were asked to retain the information and consent form and return the completed

190 survey with other paperwork required for the visit.

$191 \quad$ Sample

192 All women who entered a Planned Parenthood clinic in San Jose and

193 requested EC were asked to complete the survey. There were no demographic

194 criteria for participation in the study with the exception of gender and age. Only

195 women are able to obtain EC, and only women were asked to complete the

196 survey. Clients must have been at least 18 years of age in order to consent to

197 participate in the study.

198 The survey took approximately 10 minutes to complete. The average wait

199 time for a clinic visit was 20-30 minutes, so there were no additional time

200 constraints for the clients asked to participate in the study. There was no

201 compensation awarded to the subjects for participating in the study. There were

202 no direct risks of completing the study with the exception of any unforeseen

203 mental anguish that may be caused by the sensitive subject matter of the questions

204 related to sexuality and contraception.

$205 \quad$ Instruments

206 Levinson (1998) developed a CSE scale that has been utilized in the

207 analysis of contraceptive behavior, specifically motivational barriers to

208 contraceptive use among sexually active teenagers. It measures strength of

209 conviction that one can control sexual and contraceptive situations in order to 


\section{Running Head: SELF-EFFICACY IN EMERGENCY CONTRACEPTION}

210 prevent pregnancy. The CSE tool was designed as a diagnostic tool for clinicians

211 and educators to aid in the design and assessment of interventions; it may also be

212 used as a research instrument for further work in reproductive health (Levinson,

213 1995a).

214 The 18-question Likert scale assesses CSE using situational items which

215 respondents rate on a scale from 1 (not at all true of me) to 5 (completely true of

216 me). Participants are asked to rate their congruence with behaviors in these

217 sexual and contraceptive situational vignettes (See Appendix). Higher scores

218 represent higher CSE. Item numbers $2,5,6,8,9,11,12,14$ and 15 are reverse

219 scored with a lower score representing higher CSE. Item 8, related to "discourse

220 of desire" was consistently predictive of contraceptive behavior across three of

221 the four samples in which it was analyzed (Levinson 1995a).

222 Face and content validity of the CSE tool was established by factor 223 analytic techniques that examined the scale in relation to contraceptive behavior

224 (Levinson 1986). A reliability coefficient of .73 was determined by using

225 Cronbach's alpha across investigations (Levinson 1995a).

226 Data Analysis

227 The 18 item, CSE survey and additional demographic questions yielded a 228 variety of descriptive data regarding the type of client who is utilizing EC. The 229 CSE Likert scale responses were averaged and compared to results from previous 230 studies to interpret the level of contraceptive self-efficacy in this population. 


\section{Running Head: SELF-EFFICACY IN EMERGENCY CONTRACEPTION}

231 Results

232 The sample consisted of primarily Caucasian (38.2\%) and Hispanic

$233(32.7 \%)$ women between the ages of 18 to 29 years (mean $=21$ years). Religious

234 affiliation was reported by $78.2 \%$ of the clients. The reported religious

235 affiliations were overwhelmingly Catholic/Christian. Over two thirds $(78.2 \%)$ of

236 the women reported current college attendance. See Table 1.

237 Over one fifth of the clients (21.8\%) reported no current birth control

238 method, and almost half (49.1\%) were using condoms only. The majority (69\%)

239 of these women had previously used at least one birth control method other than

240 condoms. Common birth control methods included pills, patch, and Depo

241 Provera. Almost one fourth (23.6\%) of women reported using no birth control

242 method for at least one year. Over half (50.9\%) of the respondents reported side

243 effects as a barrier to contraceptive use. See Table 2.

244 On average the clients had used EC one time in the last year, with $30.9 \%$

245 of women having used it 2 or more times. Over half $(50.1 \%)$ of women were

246 timely in getting to the clinic within the first 24 hours after unprotected

247 intercourse. Very few (5.4\%) women arrived at the clinic after 72 hours had 248 passed. See Table 3.

249 Over half (58.2\%) of the respondents were having intercourse at least once

250 a week, or $>4$ times per month. Less than one fourth $(21.8 \%)$ of the women had 


\section{Running Head: SELF-EFFICACY IN EMERGENCY CONTRACEPTION}

251 ever been pregnant. Of the pregnancies that had occurred in these women, two

252 thirds (66.6\%) ended in abortion. See Table 4

253 The analysis of the data showed that clients requesting EC in this study

254 scored higher on the CSE scale than the Sunnyvale sample on all items with the

255 exception of item 8. In comparison with the Montreal, and College samples this

256 sample scored similarly with the values reported as normative data by Levinson,

257 Wan and Beamer (1998). A graphical depiction of the mean scores for these four

258 groups is presented in Figure 1.

259 Discussion

260 Figure 1 shows a comparison of mean CSE item scores between the San Jose

261 sample discussed in this research, and the Sunnyvale, Montreal, and college

262 samples presented in Levinson Wan \&Beamer (1998) as normative data. The San

263 Jose sample showed the highest CSE scores in two factors: assumption of

264 responsibility for sexual activity and contraception, and assertiveness in

265 preventing sexual intercourse. This sample also had the highest CSE scores in 2

266 of the 5 items related to strong feelings of sexual arousal. For of the remaining

267 items related to this factor, the San Jose group scored close to the highest score.

268 However, for Item 8 the San Jose group scored the lowest. Item 8 related to

269 "discourse of desire" was found to be consistently predictive of contraceptive

270 behavior across three of the four samples in which it was previously analyzed. A

271 low score would suggest that the San Jose sample did not exercise control over 
Running Head: SELF-EFFICACY IN EMERGENCY CONTRACEPTION

272 contraceptive behavior. The San Jose group did not score as well on items related

273 to the factor of conscious acceptance of sexual activity. See Table 5

274 It is insightful that the San Jose sample scored so low in CSE on Item 8. The

275 item reads: There are times when I'd be so involved sexually or emotionally that I

276 could have intercourse even if I weren't protected (using a form of birth control).

277 This is exactly the phenomenon in which EC is indicated for use. The survey

278 results are congruent with anecdotal observations. This observation indicates that

279 these women are in need of interventions that increase their acceptance of sexual

280 activity and reproductive consequences.

281 The population who is utilizing EC is an educated group of women. They

282 adhere to the recommended time constraints of EC, and have had a great amount

283 of experience with continuous birth control methods, yet they are not currently

284 utilizing a method. Their consistent high self-efficacy scores on the CSE scale

285 related to sexual and contraceptive responsibility and assertiveness in preventing

286 sexual intercourse show much promise. Their lower CSE scores related to

287 conscious acceptance of sexual activity identify possible areas for intervention.

288 The most common barrier to continual contraception reported was side

289 effects. Specific side effects were not stated, but over half (50.9\%) of women

290 indicated that side effects were a barrier to contraceptive use. It is possible that

291 these women have analyzed the risks and benefits of continual contraception and

292 that they do not perceive it to be to their benefit to use a continuous contraceptive 


\section{Running Head: SELF-EFFICACY IN EMERGENCY CONTRACEPTION}

293 method. Given the low incidence of pregnancy, and the high percentage of

294 terminations in the presence of pregnancy, it may also be that this group of

295 women view abortion as a viable solution to an unplanned pregnancy. This is a

296 bit surprising with the reported religious affiliations of these clients. Half of the

297 clients who reported religious affiliations indicated Catholicism as their religion.

298 This may have bearing on their declination of contraceptives, but does not explain

299 the high proportion of abortions.

300 The conceptual framework of this study is relevant to the baseline level of 301 self-efficacy of the clients in question. Their level of self-efficacy suggests that

302 particular interventions related to recommendations for the enhancement of self-

303 efficacy in the client may be needed. It is integral that individuals have

304 confidence in their ability to contracept. The use of interventions based in self-

305 efficacy ensures that knowledge will be transmitted and that the client will gain

306 the confidence needed to integrate the feelings of self-efficacy and abilities to

307 control sexual and contraceptive situations. Albert Bandura (1986) the father of

308 self-efficacy says, "Competent functioning requires both skills and self-beliefs of

309 efficacy to use them effectively" (p. 391).

310 Limitations

311 Young women become sexually active at various ages. Their sense of

312 reproductive responsibility also develops at various ages. This study was limited 
Running Head: SELF-EFFICACY IN EMERGENCY CONTRACEPTION

313 to clients who were at least 18 years old. The results of this study are specific to

314 this population, and may not be generalized to clients less than 18 years of age.

315 A significant number of Planned Parenthood clients are Spanish speaking.

316 The CSE tool was not translated into Spanish for this study. The results will be

317 generalizable only to English speaking women requesting EC. Because of the

318 possible cultural differences in the Hispanic population, study results from an

319 English-speaking population will provide guidelines for further studies of

320 culturally diverse populations.

321 The descriptive data analysis from this study revealed many interesting

322 phenomena. No correlations or tests of significance were performed.

$323 \quad$ Research Implications

324 The results of this study point to further research needed in assessing the

325 perceived barriers to contraception in clients utilizing EC. Given their high level

326 of CSE and perceived ability to control sexual situations it seems as though

327 women would be eager consumers of knowledge regarding contraceptive options.

328 Further studies on this population with regard to specific perceived side effects of

329 continual contraception would also be helpful to providers. Analysis of possible

330 reasons for the lower CSE scores related to conscious acceptance of sexual

331 activity may also provide insight.

$332 \quad$ Practice Implications 


\section{Running Head: SELF-EFFICACY IN EMERGENCY CONTRACEPTION}

333 Women who are utilizing EC require special attention. Interactions with

334 these women should assess the clients perceived barriers to contraception and

335 mutual brainstorming of possible methods that would be appropriate given the

336 client's individual needs. These women are at risk for pregnancy given their

337 frequency of intercourse and lack of contraceptive use. It is important to

338 acknowledge the client's concerns and identify contraceptives that are appropriate

339 for the specific client situation. Given the fact that these clients have utilized

340 multiple contraceptive methods in the past, it may be possible to have a more in

341 depth discussion of particular methods in comparison with one another. Self-

342 efficacy should be reinforced during interactions with these clients, but does not

343 necessarily require interventions aimed at increasing self-efficacy. Providers

344 should assess clients' conscious acceptance of sexual activity in order to promote

345 self-efficacy in this area that showed lower scores in the factor analysis. An

346 appeal to the previous experiences of the client will also aid in the adoption of

347 continual contraception.

348 Conclusion

349 There is minimal published information regarding the characteristics of

350 women utilizing EC. Analysis of the mental characteristics of the client utilizing

351 EC is essential to the development of evidence-based practice. EC is suggested

352 for use to prevent pregnancy, in the instance of a failure of a (barrier)

353 contraceptive method, or if no contraception is utilized at the time of intercourse, 


\section{Running Head: SELF-EFFICACY IN EMERGENCY CONTRACEPTION}

354 when pregnancy is not desired. The analysis of the results from the contraceptive

355 self-efficacy scale with clients requesting EC shows that these women have a high

356 level of perceived ability to control sexual and contraceptive situations and raises

357 the issue about why they are not using continual contraception. Findings from

358 this study may help to guide assessments and interventions of these clients to

359 promote optimal contraception.

360 Two major areas for assessment and intervention are (a) client reported

361 side effects of continuous contraception and (b) increasing the client's conscious

362 acceptance of sexual activity. Methods of assessment and intervention with the

363 client requesting emergency contraception may help to promote optimal

364 contraceptive utilization and ultimately the prevention of unwanted pregnancies,

365 and appropriate timing of desired pregnancies. 
Running Head: SELF-EFFICACY IN EMERGENCY CONTRACEPTION

\section{References}

367 Bandura, A. (1986), Social foundations of thought and action: A social cognitive 368 theory. Englewood Cliffs, NJ: Prentice-Hall, 390-419.

369 Bilodeau, A., Forget, G., and Tetreault, J. (1994) L'auto-efficiency relative a la

$370 \quad$ contraception chez les adolescents et les adolescents: La validation

371 francaise de l'echelle de mesure de Levinson. Canadian Journal of Public

$372 \quad$ Health $85,115-120$.

373 Coeytaux, F. \& Pillsbury, B. (2001). Bringing emergency contraception to

374 American women: The history and remaining challenges. Women's Health $375 \quad$ Issues. $11,80-86$.

376 Gold, M. A., Sucato, G. S., Conard, L. E. \& Hillard, P. J. (2004). Provision of 377 emergency contraception to adolescents: Position paper of the Society of 378 Adolescent Medicine. Journal of Adolescent Health. 35, 66-70.

379 Grossman, R. (2001). Emergency contraceptive pills can prevent abortion.

$380 \quad$ Journal of Public Health, 91, 1137-1138.

381 Hayes, M., Hutchings, J. \& Hayes, P. (2000). Reducing unintended pregnancy by 382 increasing access to emergency contraceptive pills. Maternal Child Health 383 Journal. 4, 203-208.

384 Heinrich, L. B. (1993). Contraceptive self-efficacy in college women. Journal of 385 Adolescent Health, 14, 269-276.

386 Levinson, R. A. (1986). Contraceptive self-efficacy: A perspective on teenage 


\section{Running Head: SELF-EFFICACY IN EMERGENCY CONTRACEPTION}

girls' contraceptive behavior. Journal of Sex Research, 22, 347-368.

388 Levinson, R. A. (1995a). Contraceptive self-efficacy (CSE) scale. In The Handbook of Sexuality Related Measures (pp.166-168) Thousand Oaks, CA: Sage Publications.

391 Levinson, R. A. (1995b). Reproductive and contraceptive knowledge,

392 contraceptive self-efficacy, and contraceptive behavior among teenage

393 women. Adolescence, 30(117), 65-86.

394 Levinson, R. A., Wan, C. K., \& Beamer, L. J., (1998). The contraceptive selfefficacy scale: Analysis in four samples. Journal of Youth and Adolescence, 27, 773-793.

397 Roye, C. F. \& Johnsen, J. R. (2002). Adolescents and emergency contraception. 398 Journal of Pediatric Health Care. 16, 3-9.

399 Wright, C. (1992). Factors associated with contraceptive behavior among black 400 college students. Unpublished doctoral dissertation, University of Oregon. 
Running Head: SELF-EFFICACY IN EMERGENCY CONTRACEPTION

401 Table 1.

402 Demographic Variables

\begin{tabular}{|c|c|c|c|}
\hline Characteristic & Range & Mean & SD \\
\hline Age (years) & $18-29$ & 21 & 2.71 \\
\hline Age at first intercourse & $13-22$ & 17 & 1.91 \\
\hline Ethnicity & $\mathbf{n}$ & $\%$ & \\
\hline Caucasian & 21 & 38.2 & \\
\hline Hispanic & 18 & 32.7 & \\
\hline Asian & 8 & 14.5 & \\
\hline Filipino & 4 & 7.3 & \\
\hline African American & 2 & 3.6 & \\
\hline Religion & $\mathbf{n}$ & $\%$ & \\
\hline Catholic & 21 & 38.2 & \\
\hline Christian & 21 & 38.2 & \\
\hline Christian Science & 1 & 1.8 & \\
\hline Education & $\mathrm{n}$ & $\%$ & \\
\hline College & 43 & 78.2 & \\
\hline High School & 2 & 3.6 & \\
\hline
\end{tabular}


Running Head: SELF-EFFICACY IN EMERGENCY CONTRACEPTION

403 Table 2.

404 Contraceptive Practices

\begin{tabular}{|c|c|c|}
\hline Current Birth Control Method & $\mathbf{n}$ & $\%$ \\
\hline None & 12 & 21.8 \\
\hline Condoms Only & 27 & 49.1 \\
\hline Condoms and Pills & 9 & 16.4 \\
\hline Pills & 5 & 9.1 \\
\hline Depo & 1 & 1.8 \\
\hline Ring & 1 & $\overline{1.8}$ \\
\hline \multicolumn{3}{|l|}{ Past Birth Control Method } \\
\hline None & 1 & 1.8 \\
\hline Condoms only & 16 & 29.1 \\
\hline Pills only & 2 & 3.6 \\
\hline Depo only & 3 & 5.5 \\
\hline Condoms/Pills & 20 & 36.4 \\
\hline Pills/Patch & 1 & 1.8 \\
\hline Condoms/Pills/Patch & 6 & 10.9 \\
\hline Condoms/Pills/Depo & 2 & 3.6 \\
\hline Condoms/Pills/Patch/Depo & 2 & 3.6 \\
\hline Condoms/Pills/Patch/Ring & 1 & 1.8 \\
\hline IUD & 1 & 1.8 \\
\hline \multicolumn{3}{|l|}{$\begin{array}{l}\text { How long since last on Birth } \\
\text { Control Method }\end{array}$} \\
\hline Never & 1 & 1.8 \\
\hline Currently on BCM & 22 & 40.0 \\
\hline $0-6$ months & 17 & 30.9 \\
\hline 6-12 months & 1 & 1.8 \\
\hline$>1$ year & 5 & 9.1 \\
\hline$>2$ years & 8 & 14.5 \\
\hline \multicolumn{3}{|l|}{ Barriers to Birth Control } \\
\hline Side Effects & 28 & 50.9 \\
\hline Cost & 8 & 14.5 \\
\hline Availability & 7 & 12.7 \\
\hline Parents & 2 & 3.6 \\
\hline Minimal Sexual Activity & 2 & 3.6 \\
\hline
\end{tabular}


Running Head: SELF-EFFICACY IN EMERGENCY CONTRACEPTION

405 Table 3.

406 EC Practices

\begin{tabular}{|c|r|r|}
\hline $\begin{array}{l}\text { Frequency of EC use in } \\
\text { the last year }\end{array}$ & $\mathrm{n}$ & $\%$ \\
\hline 0 & 22 & 40.0 \\
\hline 1 & 16 & 29.1 \\
\hline 2 & 12 & 21.8 \\
\hline 3 & 4 & 7.3 \\
\hline 4 & 1 & 1.8 \\
\hline $\begin{array}{l}\text { Elapsed time from } \\
\text { unprotected intercourse }\end{array}$ & & \\
\hline$<24$ & 28 & 50.1 \\
\hline $24-48$ & 16 & 29.1 \\
\hline $48-72$ & 7 & 12.7 \\
\hline $98-120$ & 1 & 1.8 \\
\hline$>120$ & 2 & 3.6 \\
\hline
\end{tabular}


Running Head: SELF-EFFICACY IN EMERGENCY CONTRACEPTION

407 Table 4.

408 Coital and Pregnancy Practices

\begin{tabular}{|c|r|r|}
\hline $\begin{array}{l}\text { Monthly frequency of } \\
\text { sexual intercourse }\end{array}$ & $\mathrm{n}$ & $\%$ \\
\hline $0-1$ & 7 & 12.7 \\
\hline $2-3$ & 16 & 29.1 \\
\hline $4-8$ & 14 & 25.5 \\
\hline$>8$ & 18 & 32.7 \\
\hline Pregnancy History & & \\
\hline Never Pregnant & 43 & 78.2 \\
\hline Ever Pregnant & 12 & 21.8 \\
\hline Ever Baby & 4 & 7.1 \\
\hline Ever Abortion & 10 & 18.2 \\
\hline Ever Miscarriage & 1 & 1.8 \\
\hline
\end{tabular}

409

410 
Running Head: SELF-EFFICACY IN EMERGENCY CONTRACEPTION

410 Table 5

411 CSE Factor Analysis

\begin{tabular}{|c|c|c|c|c|c|}
\hline Factor & Item \# & San Jose & Sunnyvale & Montreal & College \\
\hline \multirow{6}{*}{$\begin{array}{l}\text { Conscious acceptance } \\
\text { of sexual activity }\end{array}$} & $2 a$ & 2.24 & 3.99 & 1.86 & 2.02 \\
\hline & $5 a$ & 2.09 & 3.71 & 1.95 & 2.07 \\
\hline & $6 a$ & 2.04 & 4.23 & 1.93 & 2.10 \\
\hline & $12_{\mathrm{a}}$ & 2.31 & 3.41 & 1.66 & 2.37 \\
\hline & $14_{a}$ & 1.65 & 4.18 & 1.45 & 1.55 \\
\hline & $15_{a}$ & 1.40 & 4.42 & 1.34 & 1.32 \\
\hline \multirow{4}{*}{$\begin{array}{l}\text { Assumption of } \\
\text { responsibility for } \\
\text { sexual activity and } \\
\text { contraception }\end{array}$} & 1 & 4.27 & 3.57 & 3.45 & 3.69 \\
\hline & $13 a$ & 4.67 & 4.17 & 3.92 & 4.41 \\
\hline & $13 b$ & 4.02 & 3.74 & 4.02 & 3.97 \\
\hline & $13 c$ & 4.67 & 4.40 & 4.20 & 3.49 \\
\hline \multirow{3}{*}{$\begin{array}{l}\text { Assertiveness in } \\
\text { preventing sexual } \\
\text { intercourse }\end{array}$} & 4 & 4.47 & 3.98 & 3.57 & 4.00 \\
\hline & 7 & 4.16 & 3.78 & 3.16 & 3.99 \\
\hline & $13 \mathrm{~d}$ & 4.22 & 3.55 & 2.91 & 4.01 \\
\hline \multirow{5}{*}{$\begin{array}{l}\text { Strong feelings of } \\
\text { sexual arousal }\end{array}$} & 3 & 4.42 & 4.39 & 4.31 & $4 . \overline{47}$ \\
\hline & $8_{a b}$ & 3.11 & 2.88 & 2.10 & 2.18 \\
\hline & $9 a$ & 1.40 & 4.57 & 1.74 & 1.64 \\
\hline & 10 & 3.31 & 2.98 & 2.90 & 2.80 \\
\hline & $11_{a}$ & 1.67 & 4.42 & 1.44 & 1.70 \\
\hline
\end{tabular}

413 Note. Highlighted scores indicate greatest level of self-efficacy

$414{ }^{a}$ Indicates reverse scored items.

$415{ }^{b}$ Indicates item with consistent predictability of contraceptive behavior 
Running Head: SELF-EFFICACY IN EMERGENCY CONTRACEPTION

416

Figure 1. CSE Mean Score Comparison

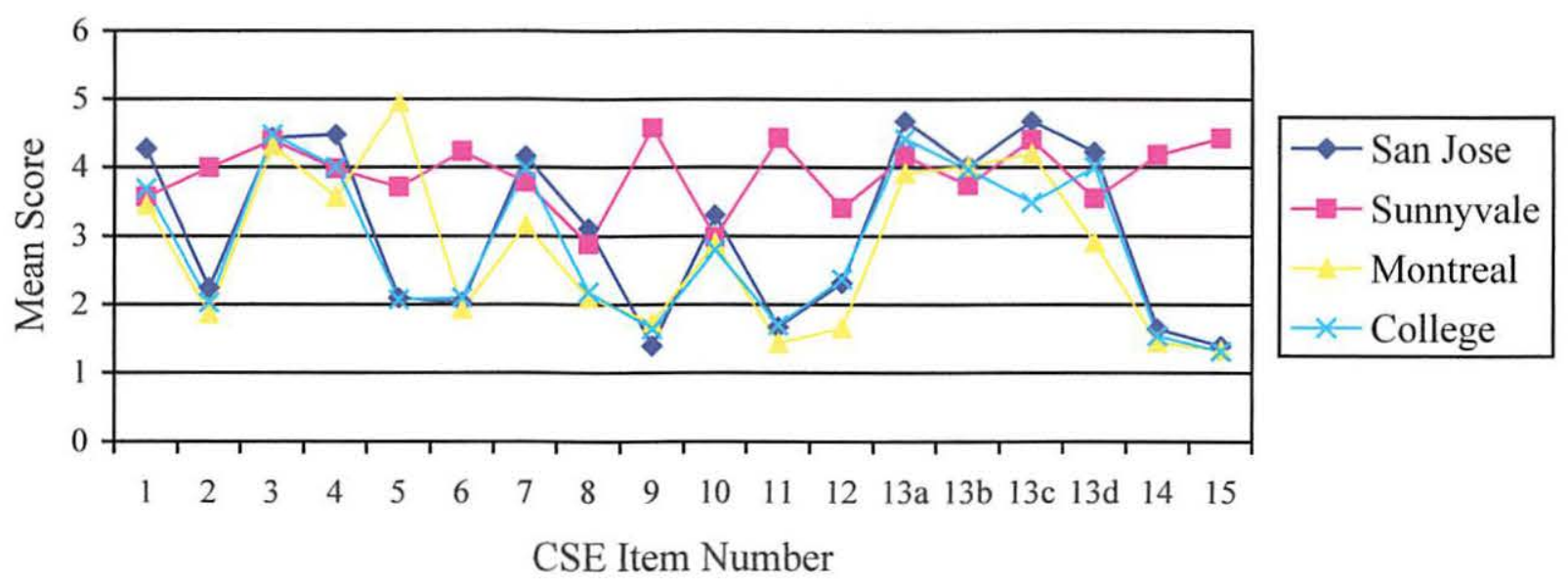

417

418

419 
Running Head: SELF-EFFICACY IN EMERGENCY CONTRACEPTION

420 Figure 1. Item numbers $2,5,6,8,9,11,12,14,15$ are reverse scored with lower 421 values indicating higher CSE

422 
Running Head: SELF-EFFICACY IN EMERGENCY CONTRACEPTION

Appendix

Perceived Sexual/Reproductive Control: Contraceptive Self-Efficacy Tool

The items following are a list of statements. Please rate each item on a 1 to 5 scale according to how true the statement is of you. Using the scale, circle one number for each question:

$$
\begin{aligned}
& 1=\text { Not at all true of me } \\
& 2=\text { Slightly true of me } \\
& 3=\text { Somewhat true of me } \\
& 4=\text { Mostly true of me } \\
& 5=\text { Completely true of me }
\end{aligned}
$$

1) 12345 When I am with a boyfriend, I feel that I can always be responsible for what happens sexually with him.

2) 12345 Even if a boyfriend can talk about sex, I can't tell a man how I really feel about sexual things.

3) 12345 When I have sex, I can enjoy it as something that I really wanted to do.

4) 12345 If my boyfriend and I are getting "turned on" sexually and I do not really want to have sexual intercourse (go all the way, get down), I can easily tell him "No" and mean it.

5) 12345 If my boyfriend didn't talk about the sex that was happening between us, I couldn't either.

6) 12345 When I think about what having sex means, I can't have sex so easily.

7) 12345 If my boyfriend and I are getting "turned on" sexually and I don't really want to have sexual intercourse (go all of the way, get down), I can easily stop things so that we don't have intercourse.

8) 12345 There are times when I'd be so involved sexually or emotionally that I could have intercourse even if I weren't protected (using a form of birth control)

9) 12345 Sometimes I just go along with what my date wants to do sexually because I don't think that I can take the hassle of saying what I want. 


\section{Running Head: SELF-EFFICACY IN EMERGENCY CONTRACEPTION}

461 10) 12345 If there were a man (boyfriend) to whom I was very attracted

462 physically and emotionally, I could feel comfortable telling that I wanted to have 463 sex with him.

465 11) 12345 I couldn't continue to use a birth control method if I thought that my

12) 12345 It would be hard for me to go the drugstore and ask for foam (Encare Ovals, a diaphragm, a pill prescription, ect,) without feeling embarrassed.

13) If my boyfriend and I were getting really heavy into sex and moving towards intercourse and I wasn't protected...
A) 12345 I could easily ask him if he had protection (or tell him that I didn't).

B) 12345 I could excuse myself to put in a diaphragm or foam (if I used them for birth control).

C) 12345 I could tell him I was on the pill or had an IUD (if I used them for birth control).

D) 12345 I could stop things before intercourse, if I couldn't bring up the subject of protection.

14) 12345 There are times when I should talk to my boyfriend about using contraceptives, but I can't seem to do it in the situation.

15) 12345 Sometimes I end up having sex with a boyfriend because I can't find a way to stop it.

490 A perspective on teenage girls' contraceptive behavior" by R. A. Levinson

491 (1986). Journal of Sex Research, 22, 351. 
Running Head: SELF-EFFICACY IN EMERGENCY CONTRACEPTION

492

Age: Race:

Religion:

Occupation: Student: (circle one) High School College N/A

1) What Birth Control method are you currently using? None Condoms Pills Patch Ring IUD Other

2) What Birth Control methods have you used in the past? (Circle all that apply)
None Condoms Pills Patch Ring IUD Othe

3) How long has it been since you were using a method?

I am currently on a method $0-6$ months $6-12$ months $>1 \mathrm{yr}>2 \mathrm{yrs}$

505

506

507

508

509

4) How many times have you used EC (emergency contraception) in the past 12 months?

5) How long has it been since your last unprotected intercourse?

$<24 \mathrm{hrs} \quad 24-48 \mathrm{hrs} \quad 48-72 \mathrm{hrs} \quad 72-96 \mathrm{hrs} \quad 98-120 \mathrm{hrs} \quad>120 \mathrm{hrs}$

6) At what age did you first have sexual intercourse?

510

7) How often do you have sexual intercourse?

511

512

513

514

0-1 times/month 2-3 times/month 4-8times/month $>8$ times/month

8) What barriers do you feel keep you from using a birth control method?

Cost Side Effects Availability of method Other

9) Have you ever been pregnant? Yes No

Live Births Abortions Miscarriages 